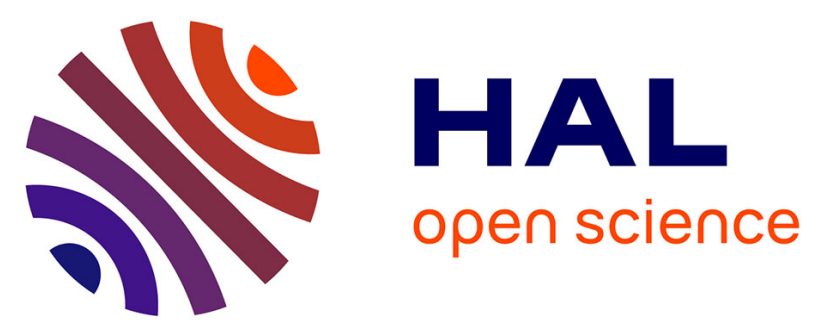

\title{
Synthesis and characterization of molecularly imprinted polymers for the selective extraction of oxazepam from complex environmental and biological samples
}

Fanny Varenne, Porkodi Kadhirvel, Pauline Bosman, Loïc Renault, Audrey Combès, Valérie Pichon

\section{To cite this version:}

Fanny Varenne, Porkodi Kadhirvel, Pauline Bosman, Loïc Renault, Audrey Combès, et al.. Synthesis and characterization of molecularly imprinted polymers for the selective extraction of oxazepam from complex environmental and biological samples. Analytical and Bioanalytical Chemistry, In press, 10.1007/s00216-021-03268-w . hal-03279333

\section{HAL Id: hal-03279333 \\ https://hal.sorbonne-universite.fr/hal-03279333}

Submitted on 6 Jul 2021

HAL is a multi-disciplinary open access archive for the deposit and dissemination of scientific research documents, whether they are published or not. The documents may come from teaching and research institutions in France or abroad, or from public or private research centers.
L'archive ouverte pluridisciplinaire HAL, est destinée au dépôt et à la diffusion de documents scientifiques de niveau recherche, publiés ou non, émanant des établissements d'enseignement et de recherche français ou étrangers, des laboratoires publics ou privés. 
Analytical and Bioanalytical Chemistry https://doi.org/10.1007/s00216-021-03268-w

Received: 21 December 2020 / Revised: 19 February 2021 /Accepted: 2 March 2021

\# Springer-Verlag GmbH Germany, part of Springer Nature 2021

\title{
Synthesis and characterisation of molecular imprinted polymers for the selective extraction of oxazepam from complex environmental and biological samples
}

Fanny Varenne ${ }^{1}$, Porkodi Kadhirvel ${ }^{1}$, Pauline Bosman ${ }^{1}$, Loïc Renault ${ }^{1}$, Audrey Combès ${ }^{1}$, Valérie Pichon $^{1,2}$.

${ }^{1}$ Laboratory of Analytical, Bioanalytical Sciences and Miniaturization, Chemistry, Biology and Innovation (CBI) UMR 8231, ESPCI Paris PSL, CNRS, PSL University, Paris, France.

${ }^{2}$ Sorbonne University, 4 Place Jussieu, 75005 Paris, France.

Corresponding Author: Professor V. Pichon, valerie.pichon@escpi.fr; ORCID number 0000-00029232-2861.

Corresponding author institution: LSABM, ESPCI-Paris, 10 rue Vauquelin, 75005 Paris, France.

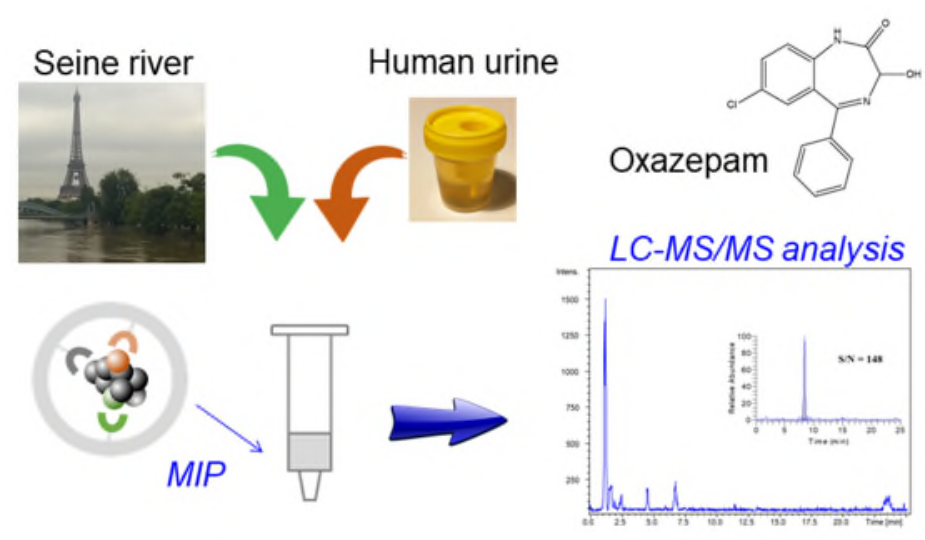

\begin{abstract}
Oxazepam, one of the most frequently prescribed anxiolytic drugs, is not completely removed from waste waters with conventional treatment processes. It can thus also be found in environmental waters at trace levels, human urine constituting the major source of contamination. This study focussed then on the development and characterisation of molecularly imprinted polymers (MIPs) for the selective solidphase extraction of oxazepam at the trace levels from environmental water and human urine samples . Two MIPs were thus synthesized and their selectivity in pure organic and aqueous medium were assayed. After optimizing the extraction procedure adapted to a large sample volume to reach a high enrichment factor, the most promising MIP was applied to the selective extraction of oxazepam from environmental waters. Extraction recoveries of $83 \pm 12,92 \pm 4$ and $89 \pm 10 \%$ were obtained using the MIP for tap, mineral and river water respectively while a recovery close to $40 \%$ was obtained on the corresponding non-imprinted polymer (NIP). Thanks to the high enrichment factors obtained, the LOQ was of $4.5 \mathrm{ng} \mathrm{L}^{-1}$ for river water. A selective extraction procedure was also developed for urine sample and gave rise to extraction recoveries close to $95 \%$ on MIP and of only $23 \%$ on NIP, which. Using the MIP, a LOQ of $357 \mathrm{ng} \mathrm{L}^{-1}$ for oxazepam in urine was obtained. The use of the MIP also allowed to limit matrix effects encountered for the quantification of the oxazepam in environmental samples and in human urine samples after extraction on Oasis HLB sorbent.
\end{abstract}

\section{Key words}

Benzodiazepines, Molecularly imprinted polymers, Solid phase extraction, LC-MS/MS, Environmental water samples, Human urine samples. 


\section{Introduction}

Oxazepam (OXA) is one of the most marketed among active benzodiazepines (BZDs) available in France for its anxiolytic properties [1] (Seresta ${ }^{\circledR}, 374$ million of marketed tablets in 2015 [2]), and is also one of the active metabolites of other BZDs [3]. It is detected in urine at concentration levels ranging from a few $\mu \mathrm{g} \mathrm{L}^{-1}$ to a few mg. $\mathrm{L}^{-1}$ in urine [4-9]. Human biological fluids as urine constitute the major source of contamination of OXA in environmental waters. It is a halogenated compound with a core structure consisting in the association of a benzene and a diazepine rings (Fig. 1), which made it resistant to the photodegradation [10] and then persistent in influents and effluents of treatment plants and surface waters. Moreover, most of sewage treatment plants are not efficient for the total removal of OXA, which explain why $80 \%$ of OXA may remain in treated wastewaters [11]. OXA has been found in influents, treated effluents from treatment plants and surface water at concentrations ranging from a few $\mathrm{ng} \mathrm{L}^{-1}$ to a few $\mu \mathrm{g} \mathrm{L}^{-1}$ [12-16] in Europe. This could therefore constitute a risk for aquatic animals, to develop a pharmacological response to OXA, and ultimately for human health [17].

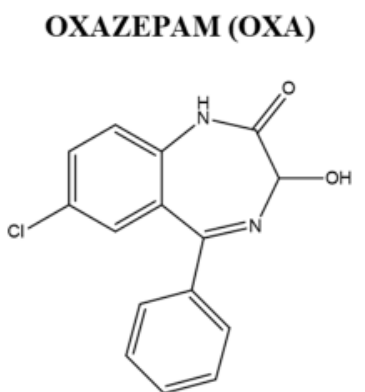

2.92

\section{NORFLURAZEPAM (NOR)}

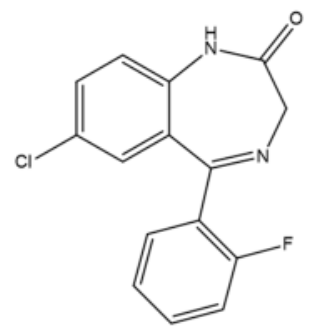

3.35

Fig. 1. Chemical structure and octanol-water partition coefficient (log P) of OXA and NOR.

As other BZDs , the analysis of OXA in environmental waters $[12,13,16,18]$ is mainly achieved by liquid chromatography coupled to mass spectrometry (LC-MS). Due to the low concentration levels in environmental waters and biological fluids, a sample treatment step by solid-phase extraction (SPE) [12, 13, 18-21] must be included in the analytical procedure in order to concentrate it. However, SPE performed with conventional sorbents ( $\mathrm{C} 18$ silicas, polymers) can lead to the co-extraction of compounds with similar physico-chemical properties and thus to co-elution in liquid chromatography which may affect the reliability of the method. An alternative to these sorbents is to use more selective materials such as molecular imprint polymers (MIPs) which have cavities that allow selective trapping of a given compound or compounds of close structure. Basically, the synthesis of a MIP is performed in the presence of a template molecule that is removed after synthesis, thus releasing cavities that are complementary in size, shape and chemical function to the template molecule. The nature and the strength of the interactions between targeted compounds and MIPs depend on the nature of the monomer, of the cross linker and of the porogen used during the synthesis process. To assess the selectivity of the retention on MIP, a non-imprinted polymer (NIP) can also be synthetized under the same conditions but without the introduction of the template molecule

Some studies focused on the selective extraction of BZDs from biological samples including hair [22, 23], serum [24, 25], plasma [26-28] or urine [25, 28] using MIPs introduced directly as particles or fibres into samples for partitioned extraction $[24,26,28]$ or as particles introduced into cartridges for exhaustive extraction (SPE) [22, 23, 25, 27]. Of these studies, only two involved the selective extraction of OXA, the main subject of these studies being the selective extraction of diazepam (DIA) and its metabolites from hair extracts [22, 23]. These works highlighted the potential of MIPs developed for DIA to extract OXA with a high extraction recovery (73-74 \%) [22, 23]. However, the evaluation of the potential of these MIPs was performed for hair extracts reconstituted in a small volume of toluene.

.The potential of a MIP capable of selectively extracting OXA from environmental waters has not yet been demonstrated. For this, considering the low levels of concentration (ng L-1) it is important to be able to percolate larger volumes of samples in order to concentrate the targeted compounds and thus to 
facilitate their further quantification in LC-MS/MS. Until now, only one study focused on the selective extraction of DIA and lorazepam from environmental waters [21]. It was carried out using a commercialized MIP whose conditions of synthesis were only partially described, only the nature of the used monomer being mentioned (methacrylic acid, MAA). Moreover, this study did not concern OXA. All these MIPs used the targeted BZDs as template molecule such as DIA [22, 23, 25-27] or clonazepam $[24,28]$. However, it has been shown that the analysis of drugs at trace levels in environmental water samples or biological samples requires the selection of a dummy template to avoid false positives and/or overestimation of drug quantities due to the risk of template leakage when applying the MIP to real samples $[29,30]$. The use of a structural analogue as template was only described for the development of a MIP-based sensors to determine OXA in pharmaceutical formulation [31].

The present work aimed to evaluate the potential of MIP to selectively extract OXA which is one of the most marketed BZDs in France and an active metabolite of other BZDs. In order to avoid the risk of leak of the template when applying the MIP to real biological or environmental samples, a BZD which is not prescribed in France and not included in the list of prioritized pharmaceutical compounds that should be monitored in French environmental waters [32] was used as dummy template: norflurazepam (NOR).

Two MIPs were then synthesized by using MAA, i.e. the most used monomers for the synthesis of MIP for BZPs, and by varying the nature of the cross-linking agent. The selection of the best synthesis conditions was achieved by comparing the retention of OXA in pure organic solvents and aqueous media on each MIP and on their corresponding NIPs. After optimization of the extraction procedure, the MIP giving rise to the best selectivity for OXA was studied in more detail by evaluating its ability to extract it from large volumes of several water samples such as drinking, mineral, and river water. The potential of this MIP to extract OXA from another complex aqueous sample, i.e. urine, was then investigated. Finally, the performance of the MIP in terms of extraction yield and clean-up efficiency for a river water sample and a urine sample was finally compared to that of the commercial sorbent, Oasis HLB polymer. During these different parts of the study, the behavior of OXA-MIP, towards others BZDs (listed as priority pharmaceutical compounds to be monitored in French environmental waters) like bromazepam (BRO), alprazolam (ALPRA), diazepam (DIA) and lormetazepam (LORM) was also studied.

\section{Materials and methods}

\subsection{Materials}

NOR (96\%) was provided by ABCR (Karlsruhe, Germany). ALPRA (analytical standard) was from Carbon Scientific (London, UK). DIA (> 98.5\%), LORM (> 98.5\%) and OXA (> 98.5\%) were supplied by Lipomed (Weil am Rhein, Germany). MAA (99\%), EGDMA (98\%), divinylbenzene (DVB, 80\%), acetone (ACS reagent, > 99.5\%), hexane (anhydrous, 95\%), ammonium hydroxyde solution (33\%), azoN,N'-bisisobutyronitrile (AIBN, 98\%) and BRO (analytical standard) were purchased from SigmaAldrich (Saint Quentin Fallavier, France). MAA and EGDMA were distilled under vacuum to remove inhibitors. Acetonitrile (ACN, HPLC-grade-ACS reagent), dichloromethane (DCM, HPLC-isocraticstabilized with ethanol), methanol (MeOH, HPLC-grade), toluene (HPLC-grade), heptane (HPLCisocratic grade) and formic acid (FA, for analysis-ACS reagent, 99\%) were provided by Carbo Erba (Val de Reuil, France). Hydrochloric acid (for analysis-ACS reagent, 32\%) and ammonium acetate (crystal extra pure) was from Merck (Darmstadt, Germany). Acetic acid (AA, glacial, anhydrous for analysis, 100\%) was from VWR (Fontenay-sous-Bois, France). Ultrapure water was provided by a MilliQ purification system from Millipore (Saint Quentin en Yvelines, France). A mixture of the six BZDs at the same concentration $\left(5000 \mu \mathrm{g} \mathrm{L}^{-1}\right)$ in ACN was used as stock solution to prepare the standard solutions and the solutions of percolation for SPE. This mixture and the standard solutions were stored at $-20^{\circ} \mathrm{C}$ until use and the solutions of percolation were prepared extemporaneously.

\subsection{Instrumentation and analytical conditions}

For small percolated volume $(1 \mathrm{~mL})$, the analyses of the fractions of percolation, washing and elution resulting from the use of the MIPs and the corresponding NIPs were carried out in LC-UV with a system composed of a liquid chromatograph (Agilent 1200 series system, Agilent Technology, Massy, France) equipped with a diode array detector controlled by the Chemstation software. OXA and other BZDs were separated with a C18 Omnispher column $(150 \times 2 \mathrm{~mm}, 5 \mu \mathrm{m}$, Varian, Middelburg, The 
Netherlands). The temperature of the column was fixed at $35^{\circ} \mathrm{C}$ and the injection volume was set at 5 $\mu \mathrm{L}$. The mobile phase consisted in a mixture of $\mathrm{ACN} / \mathrm{H}_{2} \mathrm{O} / \mathrm{FA}(35 / 65 / 0.1, \mathrm{v} / \mathrm{v} / \mathrm{v})$ with a flow rate set at $0.2 \mathrm{~mL} \mathrm{~min}^{-1}$. The BZDs were detected by UV absorbance at $240 \mathrm{~nm}$.

For higher percolated volume $(4,15,25$ and $35 \mathrm{~mL})$, LC-MS/MS analyses of the fractions of percolation, washing and elution resulting from the use of the MIPs and the corresponding NIPs were performed on the same column with a liquid chromatograph (Ultimate $3000^{\circledR}$, Thermo Scientific, Illkirch, France) hyphenated with a triple quadrupole (TQ) mass spectrometer equipped with a heated electrospray ionization source (TSQ Quantum Access MAX, Thermo Scientific). The system was controlled with the Chromeleon, Thermo TSQ Tune Master and X-Calibur softwares. The LC conditions were identical to those applied to analyse BZDs in LC-UV. The quantification of BZDs in MS was performed with MRM detection in positive mode. The spray voltage was set at $3000 \mathrm{~V}$ and the vaporiser and capillary temperatures at $350^{\circ} \mathrm{C}$ and $200^{\circ} \mathrm{C}$ respectively. The pressure of the sheath gas was fixed at $40 \mathrm{psi}$. The auxiliary and the ion sweep gas pressures were set at 5 and 0 psi respectively. The value of the skimmer offset was fixed at $20 \mathrm{~V}$. Nitrogen was used as desolvation gas and argon as the collision gas at a pressure set at $1.5 \mathrm{mTorr}$. Two transitions were monitored for each BZD and collision energy related to each transition was optimized, the calibration curves obtained by LC-UV and LC-MS/MS systems are given in Electronic Supplementary Material (Tables S.1 and S.2 respectively).The ratio between the area of the peak corresponding to the MRM transition of the quantifier and the area of the peak corresponding to the MRM transition of the qualifier ion was calculated after LC-MS/MS analysis of standard solution of the targeted compounds (Table S.2). The elution fractions resulting from the use of the MIP and of a commercial sorbent (OASIS HLB, Waters, Saint Quentin en Yvelines, France) were first analysed in MRM mode on TQ mass spectrometer in order to calculate the extraction yield for each BZD on each support. Then, the fractions were analysed with a liquid chromatograph (Agilent 1260 Infinity, Agilent Technology, Massy, France) coupled with a quadrupole-time of flight (Q-TOF) mass spectrometer equipped with an electrospray ionization source (micrOTOF-Q Brucker Daltonics, Champs sur Marne, France) in positive full scan mode $(\mathrm{m} / \mathrm{z}=100-2000)$ in order to visualize the complexity of the sample. The system was controlled with the HyStar and OtofControl softwares. The chromatographic conditions were the same as those used to analyse BZDs with LC-UV system.

\subsection{Synthesis of molecularly imprinted polymers}

Two MIPs, MIP 1 and MIP 2, were synthetized by bulk polymerization with a template/monomer/crosslinker molar ratio fixed at 1/4/20. MAA was used as monomer for both MIPs. The cross-linker used to prepare MIPs was EGDMA for MIP/NIP 1 and DVB for MIP/NIP 2. As DVB was envisaged, appropriate solvent consisting in a mixture of DCM and toluene was considered as porogen for both MIPs to promote polar interactions between the monomer and the template molecule and to allow the complete solubilisation of DVB [33]. Briefly, $333 \mu \mathrm{mol}$ of NOR, $1.3 \mathrm{mmol}$ of MAA, $6.6 \mathrm{mmol}$ of the selected cross-linker and $80 \mu \mathrm{mol}$ of AIBN were dissolved in a mixture consisting in $1.8 \mathrm{~mL}$ of $\mathrm{DCM} /$ toluene $(46 / 54, \mathrm{v} / \mathrm{v})$ in a glass tube. After vortexing, the solution was purged with a $\mathrm{N}_{2}$ stream for $20 \mathrm{~min}$ and the glass tube was sealed and incubated at $56^{\circ} \mathrm{C}$ for $24 \mathrm{~h}$. In parallel, non-imprinted polymers (NIP 1 and NIP 2) were synthetized in the same conditions but without introducing the template molecule in the polymerization mixture. Then, each polymer was crushed, ground automatically with a mixer (MIL MM 301, Retsch, Eragny sur Oise, France) and sieved using a vibratory sieve shaker (Retsch). Sedimentation of particles with size between 25 and $36 \mu \mathrm{m}$ was performed three times with $20 \mathrm{~mL}$ of a mixture of $\mathrm{MeOH} / \mathrm{H}_{2} \mathrm{O}\left(80 / 20\right.$, v/v) to remove the thinnest particles. $55 \mathrm{mg}\left(0.11 \mathrm{~cm}^{3}\right)$ of dried particles of MIP or NIP were packed between two polyethylene frits (Sigma-Aldrich) in 3-mL disposable polypropylene cartridges (Sigma-Aldrich). The packed polymers were washed with $3 \mathrm{~mL}$ of $\mathrm{MeOH}$ followed with $70 \mathrm{~mL}$ of a mixture composed of $\mathrm{MeOH} / \mathrm{AA}(90 / 10, \mathrm{v} / \mathrm{v})$ to remove the template. The washing fractions were evaporated under $\mathrm{N}_{2}$ stream and resuspended in $200 \mu \mathrm{L}$ of mobile phase prior to analysis by LC-UV. The washing step was pursued until NOR was no longer detected in the washing fractions. The polymers were finally washed with $10 \mathrm{~mL}$ of $\mathrm{MeOH}$ to remove traces of AA and stored dry at $4^{\circ} \mathrm{C}$ until use. The synthesis of the couple MIP/NIP 1 was performed in triplicate by two different operators to investigate the reproducibility of its synthesis.

\subsection{Evaluation of MIPs in pure organic media}


Two extraction procedures were applied on each couple MIP/NIP to investigate the presence of cavities on MIP, an organic solvent selected to promote the same type of interaction developed during the imprinting process was used as percolation solution. The first procedure consisted in conditioning the sorbents with $3 \mathrm{~mL}$ of hexane. Then, $1 \mathrm{~mL}$ of hexane spiked at $1000 \mu \mathrm{g} \mathrm{L}^{-1}$ with the selected BZDs was percolated through the polymers. They were washed with $1 \mathrm{~mL}$ of a mixture of toluene/hexane (50/50, $\mathrm{v} / \mathrm{v})$ and the BZDs were eluted with $1 \mathrm{~mL}$ of a mixture of $\mathrm{MeOH} / \mathrm{AA}(95 / 5, \mathrm{v} / \mathrm{v})$. Concerning the second procedure, the cartridges were conditioned with $3 \mathrm{~mL}$ of toluene and $1 \mathrm{~mL}$ of toluene spiked at $1000 \mu \mathrm{g}$ $\mathrm{L}^{-1}$ with the selected BZDs was then percolated through the sorbents. After washing the cartridges with $1 \mathrm{~mL}$ of DCM, the BZDs were eluted with $1 \mathrm{~mL}$ of a mixture of MeOH/AA $(90 / 10, \mathrm{v} / \mathrm{v})$.

For both extraction procedures, the elution fractions were evaporated under $\mathrm{N}_{2}$ stream and resuspended in $500 \mu \mathrm{L}$ of mobile phase prior to LC-UV analysis at $240 \mathrm{~nm}$.

\subsection{Evaluation of MIPs in pure aqueous media}

The MIP and NIP cartridges were conditioned with $2.5 \mathrm{~mL}$ of $\mathrm{MeOH}$ and $2.5 \mathrm{~mL}$ of ultrapure water. After percolating $1 \mathrm{~mL}$ of ultrapure water spiked at $1000 \mu \mathrm{g} \mathrm{L}^{-1}$, the polymers were washed with 300 $\mu \mathrm{L}$ of $\mathrm{HCl} 0.1 \mathrm{M}$ followed with $300 \mu \mathrm{L}$ of ultrapure water. Then, the cartridges were dried under vacuum for $20 \mathrm{~min}$. The polymers were washed with $1.5 \mathrm{~mL}$ of a mixture of DCM/hexane $(70 / 30, \mathrm{v} / \mathrm{v})$. The BZDs were eluted with $1.5 \mathrm{~mL}$ of $\mathrm{MeOH}$. The elution fractions were evaporated under $\mathrm{N}_{2}$ stream and resuspended in $200 \mu \mathrm{L}$ of mobile phase prior to LC-UV analysis.

The repeatability of the synthesis of the MIP 1 was investigated by performing three extractions procedures on each synthetized couple MIP/NIP 1. The spiking level was set at $250 \mu \mathrm{g} \mathrm{L}^{-1}$. The BZDs were eluted with $1.5 \mathrm{~mL}$ of $\mathrm{MeOH}$. The elution fractions were evaporated under $\mathrm{N}_{2}$ stream and resuspended in $200 \mu \mathrm{L}$ of mobile phase prior to analysis by LC-UV.

\subsection{Application to environmental water samples}

2.6.1. Optimization of the extraction procedure applied to large sample volume

The breakthrough volumes for both MIP/NIPs were evaluated using the same procedure described in Section 2.5 except that the percolated volume of tap water $(\mathrm{pH}=7.7 \pm 0.1$, conductivity $=510 \pm 1 \mu \mathrm{S}$ $\left.\mathrm{cm}^{-1}\right)$ was varying from 15 to $35 \mathrm{~mL}$ and spiked with the same quantity of BZD $(1 \mu \mathrm{g})$, the concentration level thus ranging from 67 to $28 \mu \mathrm{g} \mathrm{L}^{-1}$.

In order to optimize the washing conditions, the same extraction procedure described in Section 2.5 was used except that $35 \mathrm{~mL}$ of tap water spiked at $3.57 \mu \mathrm{g} \mathrm{L}{ }^{-1}$ with each BZD were percolated on MIP 1 and the polymers were washed with decreasing volume, $1.5,1.25$ or $1 \mathrm{~mL}$, of a mixture of DCM/hexane $(70 / 30, \mathrm{v} / \mathrm{v})$. The elution fractions were evaporated under $\mathrm{N}_{2}$ stream and resuspended in $500 \mu \mathrm{L}$ of mobile phase prior to analysis by LC-MS in MRM mode using the TQ analyzer.

\subsubsection{Application of MIPs to mineral and river water}

Seine river water was collected in Paris and filtered twice with glass-fiber filters (type 5, $0.7 \mu \mathrm{m}, 4.7$ $\mathrm{cm}$, Sigma-Aldrich). The optimized extraction procedure was applied in triplicate on MIP/NIP 1 to extract BZDs from $35 \mathrm{~mL}$ of Evian water $\left(\mathrm{pH}=7.9 \pm 0.1\right.$, conductivity $\left.=461 \pm 1 \mu \mathrm{S} \mathrm{cm}^{-1}\right)$ spiked at $3.57 \mu \mathrm{g} \mathrm{L}^{-1}$ and from $35 \mathrm{~mL}$ of Seine river water $\left(\mathrm{pH}=8.0 \pm 0.1\right.$, conductivity $=516 \pm 1 \mu \mathrm{S} \mathrm{cm}^{-1}$ after filtration) spiked at $0.01,0.5$ and $1 \mu \mathrm{g} \mathrm{L}^{-1}$. The sorbents were washed with $1.25 \mathrm{~mL}$ of a mixture of $\mathrm{DCM} /$ hexane $(70 / 30, \mathrm{v} / \mathrm{v})$. The conditioning and the elution steps were similar to those of the procedure described in Section 2.5. The elution fractions were evaporated under $\mathrm{N}_{2}$ stream and resuspended in 500 $\mu \mathrm{L}$ of mobile phase prior to analysis by LC-MS in MRM mode (TQ analyzer) for the quantification and only for the elution fraction corresponding to percolation of Seine river water in scan mode on a Q-TOF mass analyser for the evaluation of the complexity of the sample.

\subsubsection{Comparison of performances of the MIP with a conventional sorbent}

The extraction procedure on OASIS HLB cartridge $(3 \mathrm{~mL}, 60 \mathrm{mg}$, Waters, Guyancourt, France) was adapted from procedure described by Hummel et al. [34]. Briefly, the sorbent was conditioned with $600 \mu \mathrm{L}$ of heptane followed by $600 \mu \mathrm{L}$ of acetone, $1.8 \mathrm{~mL}$ of $\mathrm{MeOH}$ and $2.4 \mathrm{~mL}$ of ultrapure water. Then, $35 \mathrm{~mL}$ of Seine river water spiked at $0.01 \mu \mathrm{g} \mathrm{L}^{-1}$ were percolated through the sorbent. The cartridge was dried under vacuum for $1 \mathrm{~h}$. The BZDs were eluted with $1.2 \mathrm{~mL}$ of acetone. The elution 
fractions of OASIS HLB was evaporated under $\mathrm{N}_{2}$ stream and resuspended in $500 \mu \mathrm{L}$ of mobile phase before LC-MS analysis in MRM mode on TQ mass analyzer for the quantification and in scan mode on a Q-TOF mass analyser for the evaluation of the complexity of the sample.

\subsection{Application of MIPs to biological fluids}

\subsubsection{Application of MIPs to human urine samples}

The sample of urine was filtered through a $0.2 \mu \mathrm{m}$ filter (cellulose acetate, VWR) and diluted with one volume of ammonium acetate-acetic acid buffer $(0.2 \mathrm{M}, \mathrm{pH} 6.0)$. The diluted sample of urine was spiked at a concentration of $0.5,1.5$ and $15 \mu \mathrm{g} \mathrm{L}^{-1}$ (equivalent in urine) with only the BZDs retained selectively (OXA, BRO and ALPRA) and vortexed for $30 \mathrm{~s}$. The extraction procedure was applied in triplicate on MIP/NIP 1. The extraction procedure on the MIP and on the NIP was similar to the one described in the Section 2.6.2 except that $4 \mathrm{~mL}$ of the spiked diluted sample of urine were percolated through the sorbents. The elution fractions were reconstituted in $500 \mu \mathrm{L}$ of mobile phase after evaporation under $\mathrm{N}_{2}$ stream before analysis by LC-MS in MRM mode using the TQ analyzer.

\subsubsection{Comparison of performances of the MIP with a conventional sorbent}

The extraction procedure on Oasis HLB was adapted from the extraction procedure proposed by Wang et al. [35]. Briefly, the cartridge was conditioned with $2 \mathrm{~mL}$ of $\mathrm{MeOH}$ followed by $2 \mathrm{~mL}$ of ultrapure water and $2 \mathrm{~mL}$ of ammonium acetate-acetic acid buffer $(0.2 \mathrm{M}, \mathrm{pH} 6.0)$. The filtered sample urine was diluted with one volume of ammonium acetate-acetic acid buffer $(0.2 \mathrm{M}, \mathrm{pH} 6.0)$ and spiked at $0.5 \mu \mathrm{g} \mathrm{L}^{-}$ ${ }^{1}$ (equivalent in urine) with the BZDs retained selectively on MIP (OXA, BRO and ALPRA). Then, the mixture was vortexed for $30 \mathrm{~s}$ and $4 \mathrm{~mL}$ were percolated through the sorbent. The sorbent was washed with $2 \mathrm{~mL}$ of $5 \% \mathrm{MeOH}$ (with $2 \%$ ammonium hydroxyde) followed by $2 \mathrm{~mL}$ of ultrapure water. The BZDs were eluted twice with $1 \mathrm{~mL}$ of $\mathrm{MeOH}$ (fractions named $\mathrm{E} 1$ and $\mathrm{E} 2$ ). After evaporation under $\mathrm{N}_{2}$ stream, the elution fraction was resuspended in $500 \mu \mathrm{L}$ of mobile phase. The elution fractions were analysed with LC-MS in MRM mode on a TQ mass analyzer.

\subsubsection{Matrix effects during LC/MS-MS analysis}

A blank filtered urine sample was diluted two times with ammonium acetate-acetic acid buffer $(0.2 \mathrm{M}$, pH 6.0) and vortexed for $30 \mathrm{~s} .4 \mathrm{~mL}$ of this solution were percolated through each sorbent. The resulting elution fractions were evaporated under $\mathrm{N}_{2}$ stream and resuspended in $500 \mu \mathrm{L}$ of standard of $2 \mu \mathrm{g} \mathrm{L}^{-1}$ diluted in mobile phase. The extraction procedure was repeated three times. All fractions were analysed with LC-MS in MRM mode on a TQ mass spectrometer and the ratio between the area of the peak corresponding to the MRM transition of the quantifier ion and the area of the peak corresponding to the MRM transition of the qualifier ion was used to confirm the identification of each targeted compound. The matrix effects were evaluated by comparing the area of peaks of BZDs of a standard at $2 \mu \mathrm{g} \mathrm{L}^{-1}$ prepared in pure media with those of the elution fractions issued of the MIP 1 or of the conventional sorbent spiked at the same concentration just before the LC/MS-MS injection. The matrix effects (ME) were defined as $M E=100 \times \frac{\text { Area of BZD in the elution fraction }}{\text { Area of standard }}$.

\section{Results and discussions}

\subsection{Choice of the synthesis conditions}

The aim of this work was to develop a selective extraction procedure based on a MIP for the determination of OXA that should be monitored at the trace levels in environmental waters (concentrations ranging from a few $n g \mathrm{~L}^{-1}$ to a few hundred $\mathrm{n} \mathrm{L}^{-1}$ in French rivers [16,32]).

The synthesis of a MIP implies the careful selection of a template molecule to lead to the formation of cavities capable of recognizing target analytes. However, when using a MIP developed for the trace analysis of a drug in environmental waters, leakage of even a small amount of the template molecule (< $4.7 .10^{-5} \%$ of quantity of template molecule introduced for synthesis) could lead to a false positive response. [33]. In order to circumvent this problem, a structural analogue, NOR, which is not one of the 
targeted BZDs detected in French environmental water samples [32], was then selected as template molecule for the synthesis of the MIPs (see structure of NOR and OXA in Fig. 1). Except in one publication that used 2-(trifluoromethyl)acrylic acid as monomer [24], the MAA was used as acidic monomer in association with ethylene glycol dimethacrylate (EGDMA) as cross-linker [22, 23, 25-27] with a template/monomer/cross-linker molar ratio of 1/4/20 [24-26] or 1/6/30 [23, 27] in toluene [25] or in chloroform [22, 23, 26, 27] as porogen. Therefore, to limit the number of synthesis conditions to be screened, MAA was also selected as monomer for its ability to develop polar interactions with NOR and OXA but the effect of the nature of the cross-linker on the retention properties was investigated by synthesizing MIPs either with EGDMA (MIP/NIP 1), often associated with MAA for MIP synthesis, either with divinylbenzene (DVB), selected for its ability to develop $\pi$ - $\pi$ interaction with compounds having aromatic groups (MIP/NIP 2). In order to allow the complete solubilisation of the polymerization mixture, the syntheses were performed in a DCM/toluene mixture $(46 / 54, \mathrm{v} / \mathrm{v})$ as porogen. These nonprotic solvents should promote the expected $\mathrm{H}$ bonds between the template and the monomer during the polymerization process.

\subsection{Characterization of the MIPs in pure organic media}

The potential of retention of both MIPs was first studied by percolating $1 \mathrm{~mL}$ of OXA and NOR i.e. the template molecule, diluted in hexane, a non-protic solvent selected to favour $\mathrm{H}$ bonds. The contribution of cavities to their retention was evaluated by the comparison of extraction yields obtained on the MIPs and their corresponding NIPs. The polymers were washed with $1 \mathrm{~mL}$ of a mixture toluene/hexane and both BZDs were eluted with a mixture $\mathrm{MeOH} / \mathrm{AA}$ in order to disrupt expected polar interactions. The extraction yields of OXA and NOR in the elution fraction were similar (close to 100\%) for MIP and NIP 1 and for MIP and NIP 2 illustrating the non-contribution of the cavities supposed to be formed in the retention process (data not shown). To limit the retention on the NIP while keeping the retention on the MIP that must be stronger than on NIP if cavities were formed, the polarity of the solvents involved in the extraction procedure has been slightly increased. Thus, hexane was replaced by toluene as percolating solvent and the washing step was performed with $1 \mathrm{~mL}$ of DCM, the elution step being again carried out with a mixture of $\mathrm{MeOH} / \mathrm{AA}$. Extraction yields in the percolation, washing and elution fractions are shown in Fig. 2 for OXA and NOR but also for other BZDs that can be found in French water, i.e BRO, ALPRA LORM and DIA which structure are given in supplementary material (Fig. S.1). Higher extraction yields were obtained for OXA, NOR and BRO in the elution fraction of the both MIPs than in that of the corresponding NIPs, thus indicating the presence of specific cavities in the MIPs.. In contrast, ALPRA, LORM and DIA are weakly retained by both MIPs. The extraction profiles obtained for both couples of MIPs/NIPs being similar, it was not possible to select the most suitable MIP for the selective extraction of OXA at this stage of the study. As the final purpose of the study was to use the MIP synthesized to extract OXA from environmental waters, a deeper evaluation of MIPs was achieved in aqueous media.
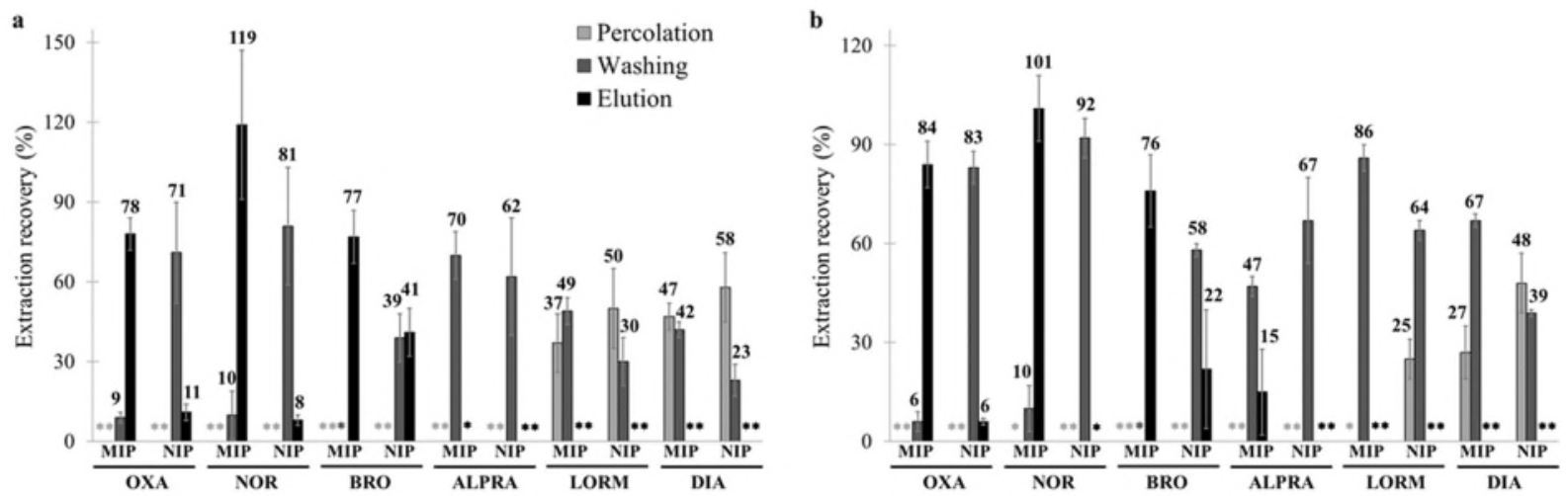

Fig. 2. Extraction profiles obtained after the percolation of $1 \mathrm{~mL}$ of toluene spiked at $1000 \mu \mathrm{g} \mathrm{L}^{-1}$ with each BDZ on (a) MIP/NIP $1(\mathrm{n}=3)$ and on (b) MIP/NIP $2(\mathrm{n}=3)$. Extraction procedure: washing with $1 \mathrm{~mL}$ of DCM, elution with $1 \mathrm{~mL}$ of MeOH/AA (90/10, v/v). The quantification was performed by LC-UV at $240 \mathrm{~nm}$. *: Unquantifiable $(\mathrm{LOD}<$ value < LOQ), **: Not detectable (value < LOD). 


\subsection{Retention of target analytes in pure aqueous media}

It was already demonstrated by our group that, with methacrylate-based MIPs, divalent cations contained in real aqueous samples can replace the protons of the carboxylic acid groups present in MIPs during the percolation step [36]. This cation exchange can compromised the establishment of polar interactions (such as hydrogen bonds) necessary for selective retention of the target analytes on MIPs. To circumvent this problem, after the percolation of aqueous samples, the interaction sites can be regenerated by a washing of the MIPs with aqueous hydrochloric acid $0.1 \mathrm{M}$ followed by ultrapure water [36]. A washing step with a non-water miscible solvent (mixture of DCM/hexane) being also envisaged, the polymers were thus dried before this washing step. This procedure was applied after the percolation of $1 \mathrm{~mL}$ of ultrapure water spiked at $1 \mathrm{mg} \mathrm{L}^{-1}$ with OXA and other BZDs and the recoveries obtained for the elution fraction of MIPs and NIPs are presented in Fig. 3. Again, OXA and NOR are selectively retained on both MIPs with extraction yields of 85 and $95 \%$ on MIP 1 (versus only 41, and 29\% for NIP 1) and 86 and $80 \%$ on the MIP 2 (versus only 57 , and $28 \%$ for NIP 2) respectively. Concerning other BZDs, MIP 1 strongly retains BRO but without any selectivity, similar recoveries being obtained on MIP 1 and NIP 1. In return, the MIP 2 allows selective retention of BRO with extraction yields significantly higher on the MIP $2(74 \%)$ than on the NIP $2(30 \%)$. Conversely, a selective retention of ALPRA is only obtained on MIP 1, with extraction yields of $30 \%$ for MIP 1 and $11 \%$ for NIP 1 , similar extraction yields being obtained on MIP 2 and NIP 2 (32 and 37\% respectively) for this compound. At last, the two MIPs do not allow the retention of LORM and DIA in aqueous media because they were poorly recovered in the elution fraction. In conclusion, the two MIPs do not present the same behaviour towards two studied BZDs, BRO and ALPRA. However, with regards to their behaviour towards the target analyte, OXA, it was not possible to select one. Therefore, some experiments on large sample volume of water were made.
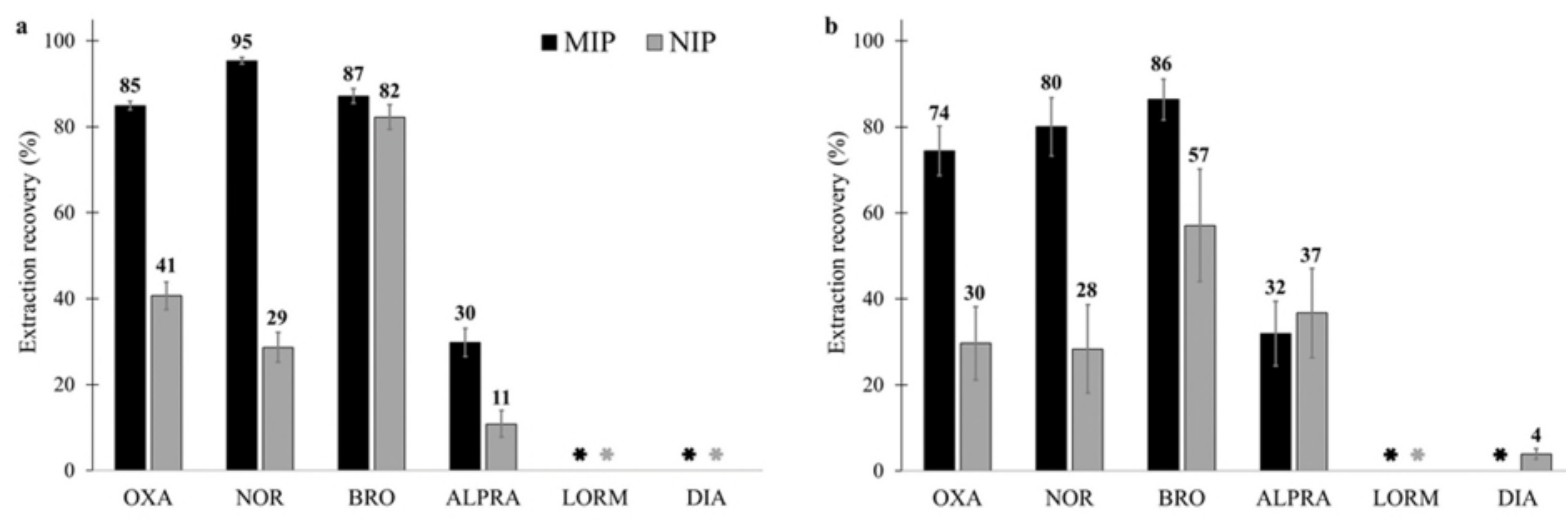

Fig. 3. Extraction recoveries in the elution fraction obtained after the percolation of $1 \mathrm{~mL}$ of ultrapure water spiked at $1000 \mu \mathrm{g} \mathrm{L}{ }^{-1}$ with each BZD on (a) MIP/NIP $1(\mathrm{n}=3)$ and on (b) MIP/NIP $2(\mathrm{n}=3)$. Extraction procedure: washing with $300 \mu \mathrm{L}$ of $\mathrm{HCl} 0.1 \mathrm{M}$ followed by $300 \mu \mathrm{L}$ of ultrapure water, drying under vacuum for 20 min, washing with $1.5 \mathrm{~mL}$ of DCM/hexane (70/30, v/v) and elution with $1.5 \mathrm{~mL}$ of $\mathrm{MeOH}$. The quantification was performed by LC-UV at $240 \mathrm{~nm}$. *: Unquantifiable (LOD < value < LOQ).

\subsection{Application to environmental water samples}

\subsubsection{Determination of the breakthrough volume}

One of the objectives of this work being to selectively extract OXA from environmental samples with a high enrichment factor to improve the sensitivity of the method. Percolation of larger sample volumes may result in the early elution of OXA because of the low but non-negligible elution strength of water itself. The breakthrough volume should thus be determined by percolating increasing volume of water samples. For these experiments, spiked tap water was selected to mimic possible matrix effects (mainly caused by large amounts of divalent cations) that may occur during the analysis of real environmental waters. Increasing volumes of tap water from 1 to $35 \mathrm{~mL}$ spiked with $1 \mu \mathrm{g}$ of OXA and of template 
NOR were then percolated through each MIP. As the aim of these experiments was to verify the retention of both compounds during the percolation step, the elution step was performed directly after percolation step, without any washing step. The analysis of this elution fraction make it possible to estimate the losses exclusively generated by the percolation step.

Significant losses have occurred during percolation step for both BZDs on MIP 2 when increasing the percolation volume from 1 to $15 \mathrm{~mL}$ (from 26 to $48 \%$ of loss for OXA and 20 to $43 \%$ for NOR respectively). In return, the percolation of up to $35 \mathrm{~mL}$ of spiked tap water on MIP 1 does not affect recoveries in the elution fraction of the OXA and NOR. MIP 1 was then selected for the continuation of the study; it was named MIP (and NIP for NIP 1) and the percolation volume was set at $35 \mathrm{~mL}$ thus providing a theoretical maximal enrichment factor of 70. Moreover, before applying this MIP to various real samples, the reproducibility of its synthesis was studied.

\subsubsection{Repeatability of synthesis of the MIP}

The repeatability of the synthesis of the MIP was investigated by synthesizing independently two others couples of MIP/NIP. In order to reduce the percolation time and to compare the results to previous extraction profiles, the same extraction procedure as the one described in Fig. $\mathbf{3}$ was applied in triplicate on each synthetized MIP/ by percolating only $1 \mathrm{~mL}$ of ultrapure water spiked at $250 \mu \mathrm{g} \mathrm{L}^{-1}$ with OXA and NOR. The average recoveries obtained for the elution fractions of MIP and NIP are reported in Fig. 4. Again, the three synthesized MIPs retained selectively OXA and NOR as the recoveries obtained with MIPs (89 and 97\% respectively) were higher than those obtained with the NIPs (41 and 21\% respectively). The standard deviations associated to these recoveries on the three synthesized MIPs were lower than $10 \%$ for both compounds. They were similar to those obtained for three independent extraction procedures performed on a single MIP (one-way analysis of variance: selected $\alpha=0.01$, pvalues $>\alpha$ ). The repeatability of the synthesis of the MIP was thus acceptable.

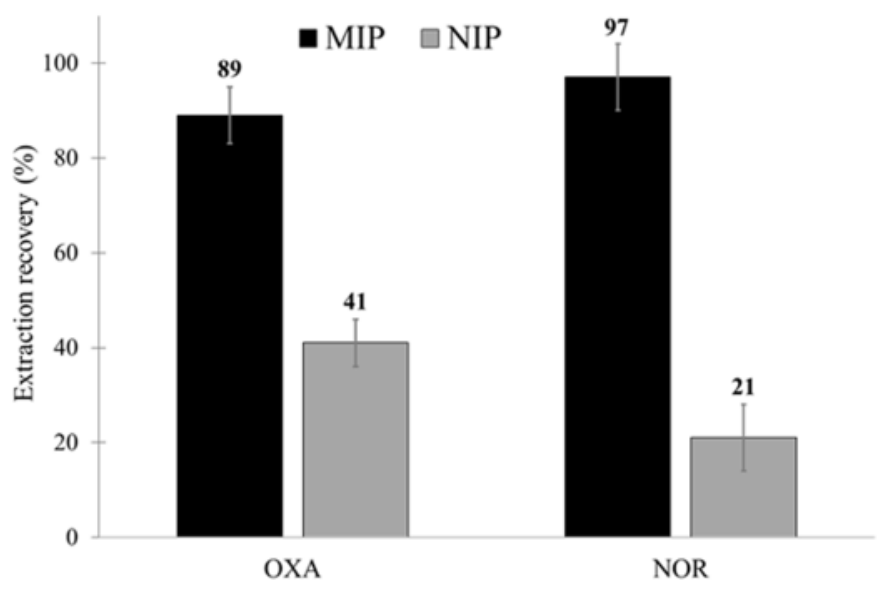

Fig. 4. Extraction recoveries in the elution fraction obtained after the percolation of $1 \mathrm{~mL}$ ultrapure water spiked at $250 \mu \mathrm{g} \mathrm{L}^{-1}$ with BZDs on three synthetized polymers MIP/NIP $1(\% \pm$ SD values, $\mathrm{n}=3$ for each synthetized sorbent). The extraction procedure was the same to the one described in Fig. 3.

\subsubsection{Retention of target analytes in environmental samples}

If the ability of this MIP to extract OXA from $35 \mathrm{~mL}$ water sample with high recoveries was demonstrated, the percolation of large volume could lead to an early elution of BZDs on the sorbents during the percolation step. It could thus be necessary to decrease the elution strength of the washing solution by reducing the volume or by modifying the composition of the washing solution in order to maintain the retention and the selectivity previously obtained for lower volumes of water (section 3.3). Therefore, the first washing steps with $\mathrm{HCl}$ solution and pure water were maintained as it should ensure the presence of proton on the carboxy moieties.but the various volumes of the washing solution $(1,5$, 1.25 and $1 \mathrm{~mL})$ of the DCM/hexane (70/30, v/v) mixture was applied. which were previously selectively retained by the MIP, BRO and ALPRA. The extraction yields obtained after the percolation of $35 \mathrm{~mL}$ 
of spiked tap water are given in Table 1. Imprinting factors (IFs) corresponding the ratio between recoveries on MIP and on NIP are also provided. The recoveries for OXA, NOR and BRO on MIP remain constant whatever the volume used for the washing step while the recovery of ALPRA increases while decreasing of the volume of washing solution. The volume of $1 \mathrm{~mL}$ has failed to provide selective retention of OXA and BRO on MIP as the IF values are close to 1 . On the other hand, a washing volume of $1.5 \mathrm{~mL}$ is too large, as it resulted in a strong decrease of the extraction yields in the elution fraction of MIP despite the very satisfactory IF values obtained in these conditions. Thus, the volume of washing solution was set at $1.25 \mathrm{~mL}$ for the further studies as it led to the best compromise between selectivity and extraction yields for OXA but also for NOR, BRO and ALPRA. It is interesting to note that the modification of the extraction procedure (higher sample volume and reduction of the washing volume) has led to the selective retention of the BRO on the MIP, whereas until now the BRO has been retained in a non-selective way. The SD values of the recoveries of BZDs were less than $20 \%(n=3)$ (Table 1) reflecting satisfactory repeatability to extract BZDs from tap water. This optimized extraction procedure was also applied to the percolation of $35 \mathrm{~mL}$ of non-spiked tap water sample. $3 \mathrm{ng}$ of NOR were detected in elution fraction of MIP thus pointing out the residual leakage of the template used for the imprinted process. This amount corresponds to less than $4.10^{-6} \%$ of the quantity of NOR introduced for the MIP synthesis. This clearly demonstrates the value of using an analogue as a template to avoid any risk of a false positive.

Table 1. Extraction recoveries (\%) in the elution fraction and corresponding IFs obtained after the percolation of $35 \mathrm{~mL}$ of tap water spiked at $3.57 \mu \mathrm{g} \mathrm{L}{ }^{-1}$ with BZDs on MIP/NIP and corresponding imprinting factor (IF) when applying different washing volume of DCM/hexane (70/30, v/v): $1(\mathrm{n}=1), 1.25(\mathrm{n}=3)$ and $1.5 \mathrm{~mL}(\mathrm{n}=1)$. The extraction procedure was the same than in Fig. 3 except for the washing step. The quantification was performed by LC-MS in MRM mode.

\begin{tabular}{cccccccccc}
\hline \multirow{2}{*}{ BZD } & \multicolumn{2}{c}{$\mathrm{V}_{\text {washing }}=1 \mathrm{~mL}$} & \multicolumn{2}{c}{$\mathrm{V}_{\text {washing }}=1.25 \mathrm{~mL}$} & \multicolumn{3}{c}{$\mathrm{V}_{\text {washing }}=1.5 \mathrm{~mL}$} \\
& MIP & NIP & $I F$ & MIP & NIP & $I F$ & MIP & NIP & $I F$ \\
\hline OXA & 71 & 61 & 1.2 & $83 \pm 12$ & $41 \pm 2$ & $2.0 \pm 0.3$ & 78 & 30 & 2.6 \\
\hline NOR & 82 & 39 & 2.1 & $104 \pm 14$ & $26 \pm 1$ & $4.0 \pm 0.3$ & 115 & 19 & 6.1 \\
\hline BRO & 98 & 73 & 1.3 & $88 \pm 18$ & $62 \pm 6$ & $1.4 \pm 0.3$ & 79 & 50 & 1.6 \\
\hline ALPRA & 60 & 38 & 1.6 & $43 \pm 6$ & $24 \pm 2$ & $1.7 \pm 0.2$ & 28 & 19 & 1.5 \\
\hline
\end{tabular}

This procedure was then applied to a non-spiked Evian water. Thanks to its high and constant ion content over time, this mineral water is usually used by French water suppliers as reference water to control their analytical methods. Except the leak of the template molecule (NOR) from the MIP (3 ng) observed in the elution fraction, no targeted compounds were detected in non-spiked Evian water. $35 \mathrm{~mL}$ of Evian water spiked at $3.57 \mu \mathrm{g} \mathrm{L}^{-1}$ were thus percolated through the MIP/NIP. The extraction recoveries in the elution fraction obtained for MIP/NIP are reported in Fig. 5. The selectivity of MIP was maintained for the extraction of OXA, NOR, BRO and ALPRA from Evian water as recoveries obtained with MIP were higher than those obtained with NIP. The SD values associated to the extraction yields of OXA and others BZDs were lower than 7\% demonstrating the repeatability of the extraction procedure applied to Evian water. Altogether these results confirmed the previous results obtained for tap water in terms of extraction efficiency and selectivity.

The optimized extraction procedure was also applied to a Seine river water sample. First, a non-spiked sample of Seine river water analysed with the optimized procedure and $2.1 \pm 0.3 \mathrm{ng}$ of OXA were detected in the elution fraction of MIP indicating that Seine river water was contaminated by OXA'. This amount of OXA was considered to calculate the extraction recovery resulting from the analysis of spiked Seine river water. Moreover, the template molecule NOR was excluded from this experiment achieved at very low concentration level $\left(0.01 \mu \mathrm{g} \mathrm{L}^{-1}\right)$ as its release by the MIP $(3 \mathrm{ng})$ during elution step is 8.5 times higher than the lowest percolated quantities envisaged $(0.35 \mathrm{ng})$. 


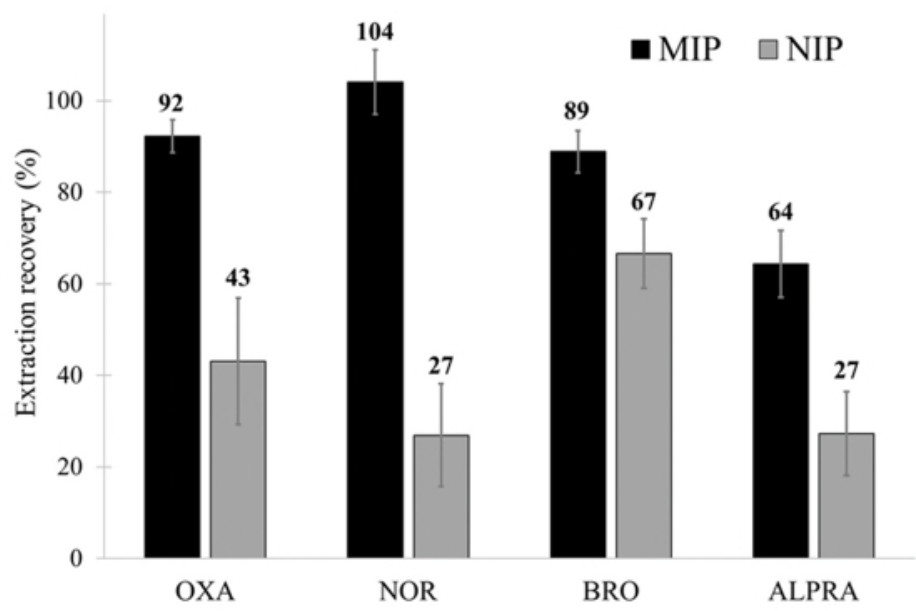

Fig. 5. Extraction recoveries in the elution fraction obtained after the percolation of $35 \mathrm{~mL}$ of Evian water spiked at $3.57 \mu \mathrm{g} \mathrm{L}^{-1}$ with each BZD $(\mathrm{n}=3)$. The extraction procedure was the same than in Fig. 3 except that: $1.25 \mathrm{~mL}$ of DCM/hexane (70/30, v/v) was used for the washing step. The quantification was performed by LC-MS in MRM mode.

The optimized extraction procedure was then applied to a Seine river water sample spiked at concentration levels closed to the lowest levels of contamination of BZDs found in environmental samples including $0.01,0.5$ and $1 \mu \mathrm{g} \mathrm{L}^{-1}[12,13,16,18]$ (Table 2). The results were similar to those obtained for spiked tap water (Table 1) or Evian water (Fig. 5). The selectivity was thus maintained for the extraction of OXA, BRO and ALPRA from Seine river water spiked at very low levels of concentration. The extraction recoveries for these BZDs were repeatable (standard deviations $<20 \%$ for OXA for the studied range of concentration) and similar whatever the considered spiking levels showing the linearity of the method applied to environmental water samples (one-way analysis of variance: selected $\alpha=0.01, \mathrm{p}$-values to OXA, BRO and ALPRA $>\alpha$ ). It is also interesting to note that OXA was present in the Seine river water at a concentration level of $66.2 \pm 8.8 \mathrm{ng} \mathrm{L}^{-1}$.

Table 2. Extraction recoveries in the elution fraction obtained after the percolation of $35 \mathrm{~mL}$ of spiked Seine river water and of $2 \mathrm{~mL}$ spiked urine diluted with $2 \mathrm{ml}$ ammonium acetate-acetic acid buffer $(0.2 \mathrm{M}, \mathrm{pH}$ 6.0) on MIP and NIP ( $\% \pm$ SD values, $\mathrm{n}=3)$. The quantification was performed by LC-MS in MRM mode. Concentration levels indicated for urine correspond to concentration value in urine before dilution.

\begin{tabular}{|c|c|c|c|}
\hline Spiking level $\left(\mu \mathrm{g} \mathrm{L}^{-1}\right)$ & BZD & MIP & NIP \\
\hline \multicolumn{4}{|l|}{ River water } \\
\hline \multirow{3}{*}{0.01} & OXA & $89 \pm 10$ & $37 \pm 12$ \\
\hline & $\mathrm{BRO}$ & $111 \pm 32$ & $54 \pm 12$ \\
\hline & ALPRA & $61 \pm 19$ & $13 \pm 3$ \\
\hline \multirow{3}{*}{0.5} & OXA & $92 \pm 7$ & $20 \pm 5$ \\
\hline & BRO & $98 \pm 3$ & $43 \pm 7$ \\
\hline & ALPRA & $62 \pm 16$ & $18 \pm 4$ \\
\hline \multirow{3}{*}{1} & OXA & $88 \pm 20$ & $37 \pm 6$ \\
\hline & BRO & $90 \pm 15$ & $60 \pm 8$ \\
\hline & ALPRA & $50 \pm 11$ & $15 \pm 3$ \\
\hline \multicolumn{4}{|l|}{ Human urine } \\
\hline \multirow{3}{*}{0.5} & OXA & $106 \pm 6$ & $<\mathrm{LOQ}$ \\
\hline & BRO & $126 \pm 8$ & $57 \pm 10$ \\
\hline & ALPRA & $38 \pm 11$ & $10 \pm 2$ \\
\hline \multirow{3}{*}{1.5} & OXA & $97 \pm 18$ & $26 \pm 5$ \\
\hline & BRO & $103 \pm 14$ & $42 \pm 3$ \\
\hline & ALPRA & $41 \pm 9$ & $16 \pm 1$ \\
\hline \multirow{3}{*}{15} & OXA & $81 \pm 12$ & $19 \pm 2$ \\
\hline & $\mathrm{BRO}$ & $93 \pm 9$ & $39 \pm 5$ \\
\hline & ALPRA & $42 \pm 5$ & $18 \pm 2$ \\
\hline
\end{tabular}




\subsubsection{Comparison of performances with a conventional sorbent}

To complete the evaluation of the potential of the MIP for the analysis of trace of OXA and other BZDs in river waters, its performance in terms of extraction yield and clean-up efficiency were compared to that provided by Oasis HLB sorbent which is commonly used to extract drugs, including BZDs, from environmental waters $[13,34]$. A previously developed extraction procedure on this commercial sorbent was adapted to the percolation volume of $35 \mathrm{~mL}$ [35]. The recovery yields in the elution fraction obtained after the percolation of $35 \mathrm{~mL}$ of Seine river water spiked at $0.01 \mu \mathrm{g} \mathrm{L}^{-1}$ with OXA, BRO and ALPRA on Oasis HLB were $98 \pm 16,98 \pm 11$ and $91 \pm 13 \%$. This demonstrates the good performance of this widely used sorbent in terms of retention. However, the elution fraction resulting from the use of Oasis HLB sorbent was more complex than the one obtained for the MIP as indicated by the presence of many peaks on the base peak LC-MS-chromatogram in scan mode $(\mathrm{m} / \mathrm{z}=300$ - 2000) (Fig. 6 a). In addition, the S/N ratio obtained for the LC-MS/MS analyses in MRM mode for the quantification of OXA in the elution fraction were higher $(\mathrm{S} / \mathrm{N}=148)$ using the MIP (Fig. 6 b) than using Oasis HLB sorbent $(\mathrm{S} / \mathrm{N}=116)$ (Fig. 6 c). The LOQ were 4.5, 1.6 and $1.2 \mathrm{ng} \mathrm{L}^{-1}$ for OXA, BRO and ALPRA respectively using the MIP. Thus, the MIP permitted to selectively extract BZDs from spiked environmental water samples at concentrations of only a few $\mathrm{n} \mathrm{L} \mathrm{L}^{-1}$. Hence, treatment of the sample on MIP with LC-MS/MS analysis allows OXA to be quantified at a concentration adapted to the analysis of real environmental water samples and with a $30 \%$ increase in sensitivity as compared to the commercial Oasis HLB sorbent (LOQ $=5.8 \mathrm{ng} \mathrm{L}^{-1}$ for OXA). In addition, as illustrated by Table S.3, the developed analytical method requires to percolate only $35 \mathrm{~mL}$ of river water through the MIP to provide similar performances to others analytical methods with a percolated volume divided by a factor of 15 to 30 (percolation volumes from 100 to $500 \mathrm{~mL}$ ).

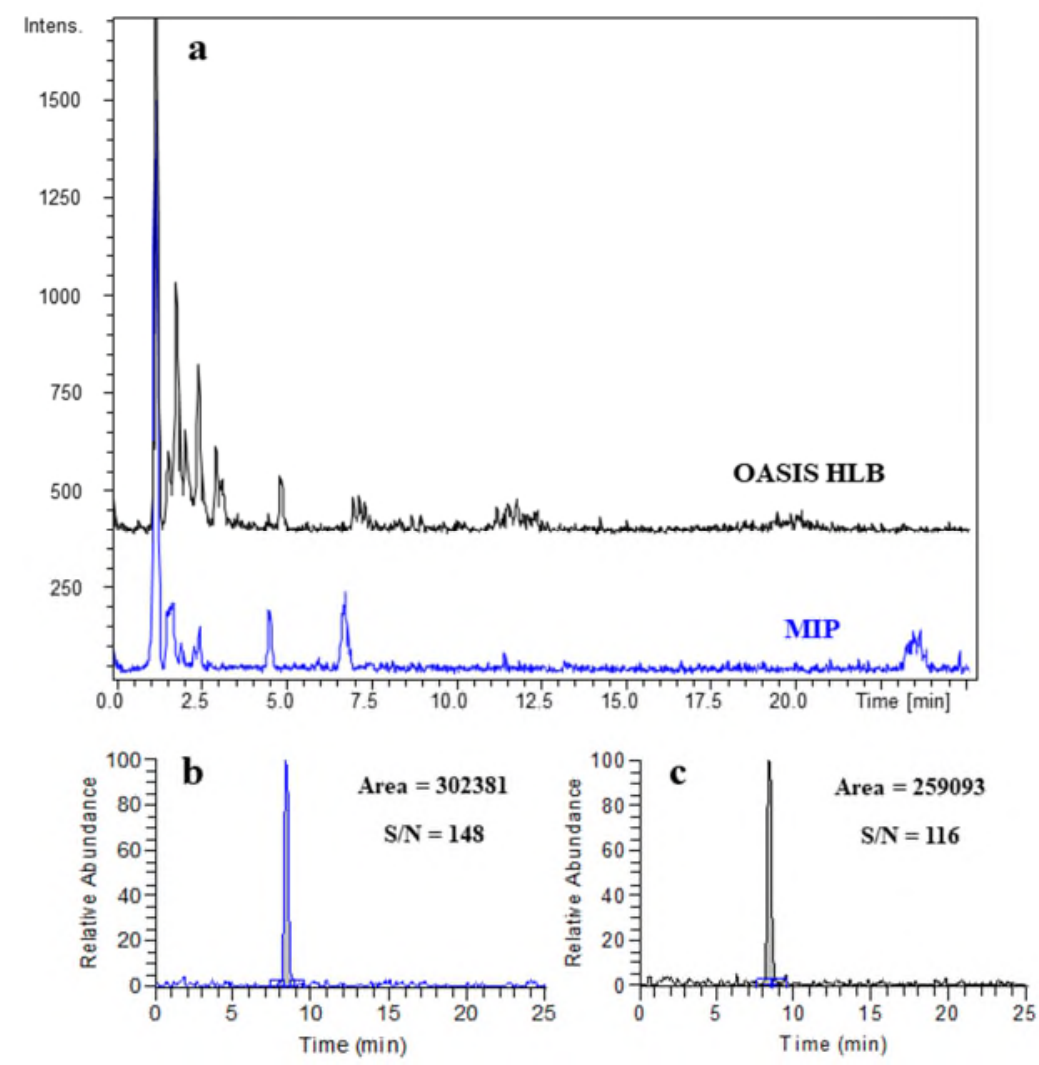

Fig. 6. Base peak LC-MS-chromatogram corresponding to the analysis of the elution fraction obtained after the percolation of $35 \mathrm{~mL}$ of Seine river water spiked at $0.01 \mu \mathrm{g} \mathrm{L}^{-1}$ with OXA, BRO and ALPRA on MIP and on Oasis HLB (a). LC-MS analysis in scan mode $(\mathrm{m} / \mathrm{z}=300-2000)$ on a Q-Tof mass spectrometer. The baseline of the chromatogram of the elution fraction obtained for Oasis HLB was artificially shifted to facilitate its reading (intensity offset: 400 a.u.). The inserts correspond to the chromatograms of the same sample provided by LC-MS in MRM mode on a TQ mass spectrometer for the quantification of OXA $(287.1 \rightarrow 241.1)$ in the elution fraction of MIP (b) and Oasis HLB sorbent (c). 


\subsection{Application to biological samples}

\subsubsection{Retention of target analytes in human urine samples}

Since human urine is one of the major pathways of environmental water contamination, it is necessary to be able to quantify OXA and other BZDs in this biological fluid beforehand. In urine, BZDs and metabolites are detected at higher concentration level than in environmental water, ranging from a few $\mu \mathrm{g} \mathrm{L}^{-1}$ to a few thousand $\mu \mathrm{g} \mathrm{L}^{-1}[4-9,37,38]$. Thus, the followed experiments were achieved at concentration levels ranging from 0.5 to $15 \mu \mathrm{g} \mathrm{L}^{-1}$ and to a reduced volume of urine sample $(2 \mathrm{~mL})$. The extraction yields obtained after the percolation of urine diluted with one volume of ammonium acetateacetic acid solution (0.2 M, pH 6.0) on MIP and NIP are presented in Table 2 for three spiking level, i.e. $0.5 \mu \mathrm{g} \mathrm{L}^{-1}, 1.5$ and finally $15 \mu \mathrm{g} \mathrm{L}^{-1}$ (equivalent in urine). It is noteworthy that the template molecule NOR was not included in these experiments, Indeed, as in the case of the analysis of Seine river water, the quantity of NOR released by the MIP during the elution step is almost 3 times higher than the lowest quantity studied ( $1 \mathrm{ng}$ ). The optimized extraction procedure was also applied to a non-spiked urine sample. No targeted compounds (OXA, BRO and ALPRA) were detected in this urine sample.

The retention and the selectivity were thus maintained for the extraction OXA and the two other BZDs from urine sample. Moreover, the extraction recoveries for these BZDs were similar whatever the considered spiking levels showing the linearity of the extraction procedure applied to human urine (oneway analysis of variance: selected $\alpha=0.01$, $\mathrm{p}$-values closed to OXA, BRO and ALPRA $>\alpha$ ). Extraction yields are repeatable as the SD were lower than $20 \%$ for the three BZDs. The LOQ values of OXA, BRO and ALPRA measured forhuman urine samples were 357, 227 and $76 \mathrm{ng} \mathrm{L}^{-1}$ respectively and below the lower concentrations of BZDs and metabolites determined in human urine (a few $\left.\mu \mathrm{g} \mathrm{L}^{-1}\right)$ and to the LOQ of already published analytical methods (Table S.3).

\subsubsection{Comparison of performances with a conventional sorbent and evaluation of matrix effects}

As for river Seine water, the performances of the MIP were compared to that of Oasis HLB ${ }^{\circledR}$ sorbent by percolating the same human urine sample spiked at $0.5 \mu \mathrm{g} \mathrm{L}^{-1}$. Extraction yields of $123 \pm 9,162 \pm 21$ and $155 \pm 10 \%$ were obtained for OXA, BRO and ALPRA respectively. These extraction yields were higher than those obtained on the MIP and well above100\%. Matrix effects affecting the quantification by LC-MS of these BZDs after the treatment of urine samples on MIP and on Oasis HLB were determined according to the procedure described in section 2.7.3 and are reported in Table 3. The matrix effects for OXA when OASIS HLB was used were negligible (exhausting of the signal of less than $10 \%$ ). However, the use of OASIS HLB sorbent clearly led to an overestimation of the amount of BRO and ALPRA in urine samples (exhausting of the signal of 47 and $44 \%$ for BRO and ALPRA respectively) and thus to an overestimation of the extraction recoveries. Conversely, using the MIP, the matrix effects were negligible for all the BZDs (below 10\%) showing that the MIP is an efficient tool to remove the interfering compounds of urine samples. It allows to overcome the problem of quantification observed when analysing the urine sample with conventional sorbents such as Oasis HLB.

Table 3. Matrix effects for BDZs for MIP and Oasis HLB sorbent ( $\% \pm$ SD values, $n=3)$. The extraction procedure was the same than in Fig. 5. The quantification was performed by LC-MS in MRM mode.

\begin{tabular}{ccc}
\hline BZD & MIP & Oasis HLB \\
\hline OXA & $103 \pm 3$ & $90 \pm 7$ \\
\hline BRO & $109 \pm 10$ & $147 \pm 10$ \\
\hline ALPRA & $105 \pm 5$ & $144 \pm 19$ \\
\hline
\end{tabular}

\section{Conclusion}

In this work, we synthetize molecular imprinted polymers in order to selectively extract OXA from environmental waters and human urine. After the screening of some synthesis conditions and the optimization of the extraction procedure adapted to different type of samples, OXA as two other BZDs, i.e. BRO and ALPRA, were selectively extract with high recoveries from real water samples (mineral, 
tap and river seine) and from urine samples. The interest of the use of a structural analogue of the target molecules as template molecule during the MIP synthesis was demonstrated since a slight progressive leakage of this molecule was observed when applying the MIP to the determination of OXA at the trace levels in real samples. High enrichment factors (between 40 and 70 for river water) and a high selectivity of the extraction procedure on MIP allow the monitoring of OXA but also for BRO and ALPRA in real samples at very low level of concentration. Indeed, LOQ values in the range 1.2 to $4.5 \mathrm{ng} \mathrm{L}^{-1}$ for river water and from 76 to $357 \mathrm{ng} \mathrm{L}^{-1}$ for urine sample were obtained. Moreover, the clean-up efficiency of the MIP was clearly demonstrated by comparing the results with that obtained with Oasis HLB as a decrease (i) of the complexity of the sample was observed on the LC-MS chromatograms and (ii) of the matrix effects for urine samples.

\section{Conflict of interest}

The authors declare that they have no conflict of interest.

\section{Compliance with ethical standards}

This is not a clinical study on humans/animals.

\section{Acknowledgment}

This work was financially supported by the French National Research Agency (ANR Program: ANR15-CE04-0012, project MIP_WQT) and by the « DIM analytics » from the region Île-de-France. The authors thank Sofiane Korchi (Trainee, Master in Chemistry, $1^{\text {st }}$ year, Sorbonne Université, Paris, France) for participation to this project.

\section{Reference}

1. Benzodiazepines and GHB - Detection and Pharmacology | Salvatore J. Salamone | Springer. https://www.springer.com/gp/book/9780896039810. Accessed 11 Jun 2020

2. Richard N, Benard A, Billioti de Gage S, Canarelli T, Cavalié P, Chatila K, Collin C, Delorme B, Leplay M, Monzon E, Pariente A, Pion C (2017) État des lieux de la consommation des benzodiazépines en France, Rapport Agence nationale de sécurité du médicament et des produits de santé

3. Mandrioli R, Mercolini L, Raggi MA (2008) Benzodiazepine metabolism: an analytical perspective. Curr Drug Metab 9:827-844 . https://doi.org/10.2174/138920008786049258

4. ElSohly MA, Gul W, Avula B, Murphy TP, Khan IA (2008) Simultaneous Analysis of ThirtyFive Benzodiazepines in Urine Using Liquid Chromatography-Mass Spectrometry-Time of Flight. J Anal Toxicol 32:547-561 . https://doi.org/10.1093/jat/32.8.547

5. Lozano-Chaves ME, Palacios-Santander JM, Cubillana-Aguilera LM, Naranjo-Rodríguez I, Hidalgo-Hidalgo-de-Cisneros JL (2006) Modified carbon-paste electrodes as sensors for the determination of 1,4-benzodiazepines: Application to the determination of diazepam and oxazepam in biological fluids. Sensors and Actuators B: Chemical 115:575-583 . https://doi.org/10.1016/j.snb.2005.10.021

6. Ahmad SM, Nogueira JMF (2019) High throughput bar adsorptive microextraction: A novel cost-effective tool for monitoring benzodiazepines in large number of biological samples. Talanta 199:195-202 . https://doi.org/10.1016/j.talanta.2019.02.004

7. Hsu R-Y, Chan S-A, Lin S-L, Lin T-Y, Chu W-L, Fuh M-R (2013) Direct quantitative analysis of benzodiazepines, metabolites, and analogs in diluted human urine by rapid resolution liquid chromatography-tandem mass spectrometry. Journal of Food and Drug Analysis 21:376-383 . https://doi.org/10.1016/j.jfda.2013.08.005

8. Wang J, Yang Z, Lechago J (2013) Rapid and simultaneous determination of multiple classes of abused drugs and metabolites in human urine by a robust LC-MS/MS method - application to urine drug testing in pain clinics. Biomed Chromatogr 27:1463-1480 . https://doi.org/10.1002/bmc.2945

9. Borrey D, Meyer E, Lambert W, Van Peteghem C, De Leenheer AP (2001) Simultaneous determination of fifteen low-dosed benzodiazepines in human urine by solid-phase extraction 
and gas chromatography-mass spectrometry. J Chromatogr B Biomed Sci Appl 765:187-197 . https://doi.org/10.1016/s0378-4347(01)00419-4

10. Calisto V, Domingues MRM, Esteves VI (2011) Photodegradation of psychiatric pharmaceuticals in aquatic environments - Kinetics and photodegradation products. Water Research 45:6097-6106 . https://doi.org/10.1016/j.watres.2011.09.008

11. Kosjek T, Perko S, Zupanc M, Zanoški Hren M, Landeka Dragičević T, Zigon D, Kompare B, Heath E (2012) Environmental occurrence, fate and transformation of benzodiazepines in water treatment. Water Res 46:355-368 . https://doi.org/10.1016/j.watres.2011.10.056

12. Baker DR, Kasprzyk-Hordern B (2011) Multi-residue analysis of drugs of abuse in wastewater and surface water by solid-phase extraction and liquid chromatography-positive electrospray ionisation tandem mass spectrometry. Journal of Chromatography A 1218:1620-1631 . https://doi.org/10.1016/j.chroma.2011.01.060

13. Racamonde I, Rodil R, Quintana JB, Villaverde-de-Sáa E, Cela R (2014) Determination of benzodiazepines, related pharmaceuticals and metabolites in water by solid-phase extraction and liquid-chromatography-tandem mass spectrometry. Journal of Chromatography A 1352:69-79 . https://doi.org/10.1016/j.chroma.2014.05.064

14. López-García E, Mastroianni N, Postigo C, Barceló D, López de Alda M (2018) A fully automated approach for the analysis of 37 psychoactive substances in raw wastewater based on on-line solid phase extraction-liquid chromatography-tandem mass spectrometry. J Chromatogr A 1576:80-89. https://doi.org/10.1016/j.chroma.2018.09.038

15. Aminot Y, Litrico X, Chambolle M, Arnaud C, Pardon P, Budzindki H (2015) Development and application of a multi-residue method for the determination of 53 pharmaceuticals in water, sediment, and suspended solids using liquid chromatography-tandem mass spectrometry. Anal Bioanal Chem 407:8585-8604 . https://doi.org/10.1007/s00216-015-9017-3

16. Camilleri J, Baudot R, Wiest L, Vulliet E, Cren-Olivé C, Daniele G (2015) Multiresidue fully automated online SPE-HPLC-MS/MS method for the quantification of endocrine-disrupting and pharmaceutical compounds at trace level in surface water. International Journal of Environmental Analytical Chemistry 95:67-81 . https://doi.org/10.1080/03067319.2014.983494

17. Brodin T, Nordling J, Lagesson A, Klaminder J, Hellström G, Christensen B, Fick J (2017) Environmental relevant levels of a benzodiazepine (oxazepam) alters important behavioral traits in a common planktivorous fish, (Rutilus rutilus). J Toxicol Environ Health Part A 80:963-970 . https://doi.org/10.1080/15287394.2017.1352214

18. Aminot Y, Litrico X, Chambolle M, Arnaud C, Pardon P, Budzindki H (2015) Development and application of a multi-residue method for the determination of 53 pharmaceuticals in water, sediment, and suspended solids using liquid chromatography-tandem mass spectrometry. Anal Bioanal Chem 407:8585-8604 . https://doi.org/10.1007/s00216-015-9017-3

19. He H, Sun C, Wang X-R, Pham-Huy C, Chikhi-Chorfi N, Galons H, Thevenin M, Claude J-R, Warnet J-M (2005) Solid-phase extraction of methadone enantiomers and benzodiazepines in biological fluids by two polymeric cartridges for liquid chromatographic analysis. Journal of Chromatography B 814:385-391 . https://doi.org/10.1016/j.jchromb.2004.10.048

20. Fernández P, Vázquez C, Lorenzo RA, Carro AM, Bermejo AM (2010) Development of a Liquid Chromatographic Method for the Simultaneous Determination of Six Benzodiazepines in Human Plasma After Solid-Phase Extraction. Analytical Letters 43:1075-1084 . https://doi.org/10.1080/00032710903492490

21. Demeestere K, Petrović M, Gros M, Dewulf J, Van Langenhove H, Barceló D (2010) Trace analysis of antidepressants in environmental waters by molecularly imprinted polymer-based solid-phase extraction followed by ultra-performance liquid chromatography coupled to triple quadrupole mass spectrometry. Anal Bioanal Chem 396:825-837 . https://doi.org/10.1007/s00216-009-3270-2

22. Anderson RA, Ariffin MM, Cormack PAG, Miller EI (2008) Comparison of molecularly imprinted solid-phase extraction (MISPE) with classical solid-phase extraction (SPE) for the detection of benzodiazepines in post-mortem hair samples. Forensic Sci Int 174:40-46 . https://doi.org/10.1016/j.forsciint.2007.03.002 
23. Ariffin MM, Miller EI, Cormack PAG, Anderson RA (2007) Molecularly Imprinted Solid-Phase Extraction of Diazepam and Its Metabolites from Hair Samples. Anal Chem 79:256-262 . https://doi.org/10.1021/ac061062w

24. Aqababa H, Tabandeh M, Tabatabaei M, Hasheminejad M, Emadi M (2013) Computer-assisted design and synthesis of a highly selective smart adsorbent for extraction of clonazepam from human serum. Mater Sci Eng C Mater Biol Appl 33:189-195 . https://doi.org/10.1016/j.msec.2012.08.029

25. Su Q, Zeng C, Tang Y, Finlow DE, Cao M (2012) Evaluation of Diazepam-Molecularly Imprinted Microspheres for the Separation of Diazepam and its Main Metabolite from Body Fluid Samples. J Chromatogr Sci 50:608-614 . https://doi.org/10.1093/chromsci/bms039

26. Abrão LC de C, Figueiredo EC (2019) A new restricted access molecularly imprinted fiber for direct solid phase microextraction of benzodiazepines from plasma samples. Analyst 144:4320 4330 . https://doi.org/10.1039/c9an00444k

27. Figueiredo EC, Sparrapan R, Sanvido GB, Santos MG, Arruda MAZ, Eberlin MN (2011) Quantitation of drugs via molecularly imprinted polymer solid phase extraction and electrospray ionization mass spectrometry: benzodiazepines in human plasma. Analyst 136:3753-3757 . https://doi.org/10.1039/c1an15198c

28. Panahi HA, Mehramizi A, Ghassemi S, Moniri E (2014) Selective extraction of clonazepam from human plasma and urine samples by molecularly imprinted polymeric beads. J Sep Sci 37:691-695 . https://doi.org/10.1002/jssc.201301144

29. Kadhirvel P, Combès A, Bordron L, Pichon V (2019) Development and application of watercompatible molecularly imprinted polymers for the selective extraction of carbamazepine from environmental waters. Anal Bioanal Chem 411:1525-1536 . https://doi.org/10.1007/s00216-01901586-8

30. Combes A, Kadhirvel P, Bordron L, Pichon V (2019) Synthesis and Characterization of Molecularly Imprinted Polymers for the Selective Extraction of Carbamazepine and Analogs from Human Urine Samples. Chromatographia 82:287-295 . https://doi.org/10.1007/s10337018-3680-4

31. Machicote RG, Castillo MA, Pacheco ME, Bruzzone L (2018) A Molecular Imprinted Polymer as a Flow-Through Optical Sensor for Oxazepam. J Anal Methods Chem 2018: . https://doi.org/10.1155/2018/6302609

32. Blum A, Allier D, Ghestem JP, Lopez B, Moly F (2011) Campagne exceptionnelle d'analyse de subsances présentes dans les eaux souterraines en 2011. Contribution à la sélection des substances à analyser et au choix des points. BRGM/RP-59135-FR

33. Kadhirvel P, Combès A, Bordron L, Pichon V (2019) Development and application of watercompatible molecularly imprinted polymers for the selective extraction of carbamazepine from environmental waters. Anal Bioanal Chem 411:1525-1536 . https://doi.org/10.1007/s00216-01901586-8

34. Hummel D, Löffler D, Fink G, Ternes TA (2006) Simultaneous Determination of Psychoactive Drugs and Their Metabolites in Aqueous Matrices by Liquid Chromatography Mass Spectrometry. Environ Sci Technol 40:7321-7328 . https://doi.org/10.1021/es061740w

35. Wang X, Wang R, Zhang Y, Liang C, Ye H, Cao F, Rao Y (2012) Extending the detection window of diazepam by directly analyzing its glucuronide metabolites in human urine using liquid chromatography-tandem mass spectrometry. Journal of Chromatography A 1268:29-34 . https://doi.org/10.1016/j.chroma.2012.10.012

36. Chapuis F, Pichon V, Lanza F, Sellergren S, Hennion M-C (2003) Optimization of the classselective extraction of triazines from aqueous samples using a molecularly imprinted polymer by a comprehensive approach of the retention mechanism. Journal of Chromatography A 999:23-33 . https://doi.org/10.1016/S0021-9673(03)00552-1

37. Chèze M, Villain M, Pépin G (2004) Determination of bromazepam, clonazepam and metabolites after a single intake in urine and hair by LC-MS/MS. Application to forensic cases of drug facilitated crimes. Forensic Sci Int 145:123-130 . https://doi.org/10.1016/j.forsciint.2004.04.066 
38. Samanidou VF, Pechlivanidou AP, Papadoyannis IN (2007) Development of a validated HPLC method for the determination of four 1,4-benzodiazepines in human biological fluids. Journal of Separation Science 30:679-687 . https://doi.org/10.1002/jssc.200600365 


\section{SUPPLEMENTARY MATERIAL}

Fig. S.1. Chemical structure and octanol-water partition coefficient $(\log \mathrm{P})$ of other BZDs included in this study.

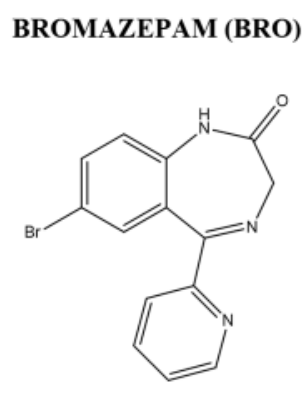

2.54
ALPRAZOLAM (ALPRA)<smiles>Cc1nnc2n1-c1ccc(Cl)cc1C(c1ccccc1)=NC2</smiles>

3.02

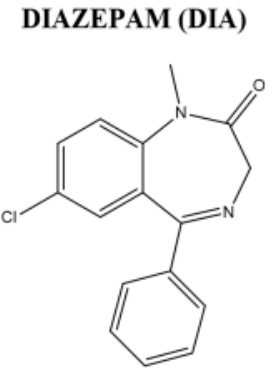

3.08
LORMETAZEPAM (LORM)

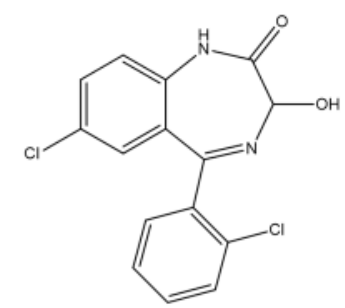

3.39

Table S.1. Performances of the LC-UV $(\lambda=240 \mathrm{~nm})$ method. The calibration curves consisted of 10 points in a concentration range of 100 to $5000 \mu \mathrm{g} \mathrm{L}^{-1}$.

\begin{tabular}{ccccc}
\hline BZD & $\begin{array}{c}\text { Studied linear range } \\
\left(\mu \mathrm{g} \mathrm{L}^{-1}\right)\end{array}$ & Linear regression & $\begin{array}{c}\text { LOD }(\mathrm{S} / \mathrm{N}=3) \\
\left(\mu \mathrm{g} \mathrm{L}^{-1}\right)\end{array}$ & $\begin{array}{c}\text { LOQ }(\mathrm{S} / \mathrm{N}=10) \\
\left(\mu \mathrm{g} \mathrm{L}^{-1}\right)\end{array}$ \\
\hline BRO & $100-5000$ & $\begin{array}{c}\mathrm{y}=165 \mathrm{x} \\
\mathrm{r}^{2}=0.9985\end{array}$ & 15 & 50 \\
\hline OXA & $200-5000$ & $\begin{array}{c}\mathrm{y}=122 \mathrm{x} \\
\mathrm{r}^{2}=0.9977\end{array}$ & 33 & 110 \\
\hline ALPRA & $400-5000$ & $\begin{array}{c}\mathrm{y}=84 \mathrm{x} \\
\mathrm{r}^{2}=0.9791\end{array}$ & 90 & 290 \\
\hline NOR & $200-5000$ & $\begin{array}{c}\mathrm{y}=205 \mathrm{x} \\
\mathrm{r}^{2}=0.9983\end{array}$ & 35 & 120 \\
\hline LORM & $200-5000$ & $\begin{array}{c}\mathrm{y}=176 \mathrm{x} \\
\mathrm{r}^{2}=0.9983 \\
\mathrm{y}=97 \mathrm{x}\end{array}$ & 35 & 110 \\
\hline DIA & $200-5000$ & \begin{tabular}{c}
$\mathrm{r}^{2}=0.9973$ \\
\hline
\end{tabular}
\end{tabular}


Table S.2. Performances of the LC-MS/MS method. Calibration curves consisted of 11 points in the concentration range from 0.1 to $500 \mu \mathrm{g} \mathrm{L}^{-1}$.

${ }^{a}$ Ratio between the area of the peak corresponding to the MRM transition of the quantifier and the area of the peak corresponding to the MRM transition of the qualifier

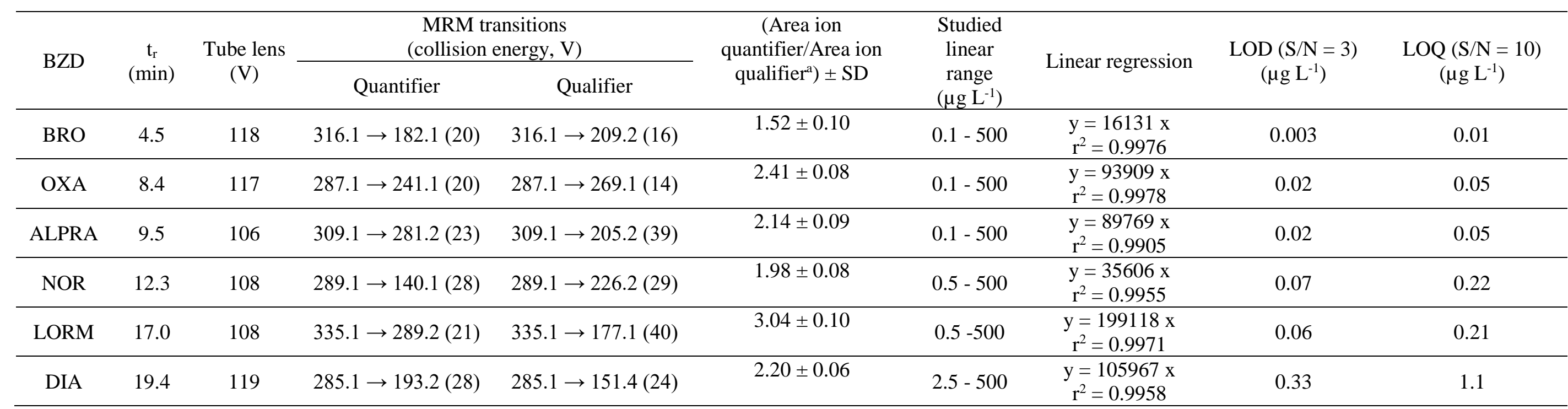

Table S.3. Comparison between already published analytical methods for the quantification of BZDs in environmental water samples and urine samples and the performance of the developed method in this work.

\begin{tabular}{cccccc}
$\begin{array}{c}\text { Number of studied } \\
\text { BZDs }\end{array}$ & $\begin{array}{c}\text { Sorbent used for } \\
\text { SPE }\end{array}$ & Type of sample & $\begin{array}{c}\text { Percolated volume } \\
(\mathrm{mL})\end{array}$ & $\begin{array}{c}\text { Extraction } \\
\text { recoveries } \\
(\%)\end{array}$ & $\begin{array}{c}\text { LOQ } \\
\left(\mathrm{ng} \mathrm{L} \mathbf{L}^{-1}\right)\end{array}$ \\
\hline Environmental applications & & & & & \\
\hline $23^{\mathrm{a}}$ & Oasis HLB & Effluent & 200 & $88-122$ & $0.1-13.2$ \\
\hline 2 & MIP & River water & 100 & 6,68 & 12,14 \\
\hline 2 & Oasis HLB & River water & 100 & 99,103 & $0.9,9.1$ \\
\hline $4^{\text {a }}$ & HLB SPE Disk & Effluent & 500 & $77.4-104.3$ & $6-55$ \\
\hline
\end{tabular}




\begin{tabular}{|c|c|c|c|c|c|c|}
\hline $4^{\mathrm{a}}$ & Oasis HLB & $\begin{array}{l}\text { Surface and } \\
\text { groundwater }\end{array}$ & 500 & $83-106$ & 10 & [40] \\
\hline $7^{\mathrm{a}}$ & Oasis MCX & River water & 500 & $21-93$ & $0.5,1.0$ & [12] \\
\hline $7^{\mathrm{a}}$ & Oasis MCX & Effluent & 100 & $10-110$ & $3.0-20.9$ & [12] \\
\hline $7^{\mathrm{a}}$ & Oasis MCX & River water & 200 & $93-114$ & $\begin{array}{c}0.192-1.1 \\
\text { (LOD) }\end{array}$ & [18] \\
\hline $3^{\mathrm{a}}$ & MIP & River water & 35 & $61-111$ & $1.2-4.5$ & $\begin{array}{l}\text { This } \\
\text { work }\end{array}$ \\
\hline \multicolumn{7}{|c|}{ Applications to urine samples } \\
\hline 4 & DSC-18 & Urine & $\mathrm{ns}$ & $81-115$ & $\mathrm{~ns}$ & [38] \\
\hline $4^{\mathrm{a}}$ & Oasis HLB & Urine & $0.1-0.2$ & $94.5-100.7$ & $\mathrm{~ns}$ & [19] \\
\hline $4^{\mathrm{a}}$ & Abselut Nexus & Urine & $0.1-0.2$ & $94.8-101.0$ & ns & [19] \\
\hline $4^{\mathrm{a}}$ & Bond Elut C18 & Urine & $0.2-0.4$ & $83.5-94.5$ & ns & [19] \\
\hline $6^{\mathrm{a}}$ & Oasis HLB & Urine & 2 & $65-122$ & $500-5000$ & [35] \\
\hline 2 & MIP & Urine & 5 & 87.2 - 90.4 & $21500-24500$ & [25] \\
\hline $3^{\mathrm{a}}$ & MIP & Urine & 4 & $38-126$ & $76-357$ & $\begin{array}{l}\text { This } \\
\text { work }\end{array}$ \\
\hline
\end{tabular}

${ }^{\mathrm{a}} \mathrm{OXA}$ was among of the targeted BZDs ns: not specified. 